\title{
Hjerneoperasjon i våken tilstand
}

Hjerneoperasjon i våken tilstand representerer en alternativ operasjonsmetode. Artikkelen gir innblikk i hvordan pasienten opplever inngrepet og hva som er viktig for pasienter som skal gjennomføre et slikt inngrep.

\section{Forfatter}

\section{Anders Aasheim}

Anestesisykepleier

Akuttklinikken, OUS, Rikshospitalet

\section{Nøkkelord}

\section{$\begin{array}{llllll}\text { Kraniotomi Våken Operasjon Opplevelse Anestesi Forberedelse } & \end{array}$}

Sykepleien Nett 2017 105(63977)(e-63977)

DOI: https://doi.org/10.4220/Sykepleienn.2017.63977

HOVEDBUDSKAP

Ved at operasjonen i hjernen foregår mens pasienten er våken, får kirurgen anledning til å vurdere pasientens verbale, kognitive og/eller motoriske og sensoriske respons under inngrepet. Slik kan en unngå å skade, for eksempel, språkfunksjon eller motorisk funksjoner. Studien, artikkelen viser til, dokumenterer at pasienter som gjennomgår våken kraniotomi har lite ubehag eller smerter under, eller i etterkant av operasjonen. Men det fremkommer at det er et forbedringspotensial av pre- og postoperativ informasjon.

\section{Bakgrunn}


Hjerneoperasjonen våken kraniotomi gjør det mulig å operere svulster, lesjoner, arterio-venøse malformasjoner (AVM) og liknende i nærheten av sentrale områder i hjernen. Reseksjon av tumor ved bruk av våken kraniotomi er vist å gi signifikant bedre nevrologisk funksjon postoperativt, og at man kan fjerne mer av tumormassen (1). Funksjonsnedsettelse som følge av inngrepet er lavere hos pasienter etter våken kraniotomi sammenliknet med pasienter som får generell anestesi ved tumorreseksjon (2).

Ved såkalt «mapping» med elektrostimulering i tumorområdet kan kirurgen bedømme hvilket vev som er trygt å fjerne. Det er vist å kunne begrense vedvarende sekvele postoperativt. Ved å vurdere pasientens verbale, kognitive og/eller motoriske respons på hjernenervestimuli peroperativt, kan kirurgen omgå viktige strukturer for språk- eller motorisk funksjon. Dette kan dermed bidra til å maksimere reseksjonsgraden hos pasientene, samt minimalisere nevrologiske funksjonstap (3).

\section{三 «Pasienten vekkes etter at hjernehinnen er åpnet, men legges i narkose igjen før lukking av hjernehinne og hud.»}

Våken kraniotomi utføres i all hovedsak ved bruk av to metoder - «awake-awake», som er en metode hvor pasienten er våken gjennom hele inngrepet. Pasienten får rikelig med lokalanestesi i området ved hudsnittet, samt der hodet fikseres med klave. Dette kombineres ofte med såkalt våken sedasjon, der pasienten får tilført små doser med angstdempende og/eller smertestillende midler intravenøst.

Den andre metoden kalles «asleep-awake-asleep» (tekstboks 1), hvor pasienten er i narkose før kirurgistart. Pasienten vekkes etter at hjernehinnen er åpnet, men legges i narkose igjen før lukking av hjernehinne og hud. Her kombinerer man lokalanestesi med intravenøs anestesi og våken sedasjon. 
- Pasienten får generell anestesi med TIVA, og larynx-maske

- Hodet fikseres med klave - 3-punkts Mayfield. Det settes scalpblock og infiltrasjon i feltet

- Ved hjelp av nevronavigasjon finner man eksakt lokalisasjon av tumor

- Hudinsisjon, åpning av skalleben og dura gjøres under narkose

- Pasienten vekkes opp for monitorering og stimulering

- Tumor fjernes under pågående testing og stimulering av språk/sensibilitet/ motorikk

- Når tumorvev er fjernet får pasienten igjen sove, med TIVA med LMA. Det gjøres hemostase og lukking før vekking.

(Tekstboks 1)

\section{Metode}

Det finnes begrenset med studier som viser til pasienters opplevelser av våken kraniotomi. Formålet med denne studien var derfor å kartlegge opplevelser hos pasienter som har gjennomgått denne type operasjon. Studien har et kvalitativt, deskriptivt design, med bruk av semistrukturerte dybdeintervjuer av 6 pasienter som har blitt operert etter asleep-awakeasleep-metoden.

Rekruttering av informanter ble gjort med utvalg fra databasen «Brainpower». Inklusjonskriterier var pasienter over 18 år som har gjennomgått våken kraniotomi de siste to årene. Pasientene skulle ikke ha språkforstyrrelser eller kognitiv svekkelse. Det ble utarbeidet en intervjuguide bestående av fem åpne hovedspørsmål (tekstboks 2). Studien er godkjent av Regional komité for medisinsk og helsefaglig forskningsetikk (REK Sør-Øst) og Personvernombudet ved Oslo universitetssykehus. 
1. Hva husker du fra operasjonen? Fortell meg hva du husker (fra hele innleggelsen)? Hva tenkte du da du skulle være våken? Hva tenkte du etter at du kom hjem?

2. Hvordan opplevde du å være våken under operasjonen?

3. Hva opplevde du som den største påkjenningen?

4. Hvordan håndterte du situasjonen?

5. Hvis noe kunne vært gjort annerledes - hva hadde vært bedre for deg? Er det noe vi kunne gjort enda bedre?

(Tekstboks 2)

\section{Analyse}

Data ble analysert ved hjelp av meningskoding, meningsfortetting og meningsfortolkning som beskrevet av Kvale og Brinkmann (5). Kondensering og tematisering ble utført etter modell fra Graneheim og Lundman (6). Funnene i analysen kan oppsummeres i seks temaer: «Opplevelse av smerte», «peroperative minner», «angst», «fortrolighet», «informasjon og forberedelse» og «venting».

\section{Opplevelsen av smerte}


Tre av seks pasienter opplevde ikke smerter under inngrepet. To av pasientene oppga smerter fra klaven under inngrepet, og en pasient beskrev smerter ved stifting av huden ved avslutning. Beez og medarbeidere (7) fant at pasienter som opplevde moderat til alvorlig smerte under våken kraniotomi, tilhørte gruppen som ble operert med asleep-awakemetoden. Smertene var da forbundet med lukking av dura, mater eller hud. Pasientene i asleep-awakeasleep-gruppen opplevde lite smerter. Disse resultatene stemmer også overens med funnene til Whittle og medarbeidere (8). Manchella og medarbeidere (9) rapporterte at kun to av 26 pasienter opplevde mer enn litt smerte, og dette var knyttet til hodeklaven.

Khu og medarbeidere (10) beskrev at den perioperative smertebehandlingen må forbedres under awake-awakeoperasjoner, til tross for at pasientene opplevde smertene som tolerable. Dette støttes av blant annet Palese og medarbeidere (11). I studien til Fletcher og medarbeidere (12) nevner ikke pasientene smerte som et tema i det hele tatt.Fire av pasientene i min studie opplevde en nærmest smertefri rekonvalesens, noe de oppga som overraskende.

Smerte er et viktig tema å drøfte før operasjonen. Det er også viktig å informere om at personalet vil ha god kontroll på smertebehandlingen også når pasienten er våken. Det er viktig for anestesipersonell å være oppmerksom på pasienter som er våkne ved avslutning av operasjonen, slik at vi sikrer adekvat smertelindring ved lukking av dura og hudsnittet.

\section{Peroperative minner}


Halvparten av pasientene husket alt, to husket en del, og en husket lite. Whittle og medarbeidere (8) fant total amnesi fra operasjonen hos 20 prosent av pasientene. Manchella og medarbeidere (9) fant total amnesi hos 27 prosent av pasientene, mens Beez og medarbeidere (7) fant at 45 prosent husket inngrepet delvis, og 17,7 prosent hadde total amnesi. De pasientene som husket mye fra operasjonene, la først og fremst merke til spesielle lyder underveis. En av pasientene hørte «at man rotet oppi der.. suging og sånt» og at det var en spesiell opplevelse. Dette støttes av blant annet Fletcher og medarbeidere (12), hvor en pasient beskrev dette som «en veldig bisarr, men en behagelig opplevelse». I studiene til Khu og medarbeidere (10) og Manchella og medarbeidere (9), var de fleste av minnene til pasientene knyttet til peroperative lyder, som drilling i ben, suging og samtaler mellom fagpersonene i teamet.

\section{三 «Ingen av pasientene i studien opplevde dette som foruroligende eller angstdrivende.»}

Noen av pasientene i vår undersøkelse beskriver den peroperative testingen som slitsom. Pasientene i min studie opplevde endringer eller bortfall av funksjoner under testingen som forventet. Ingen av pasientene i studien opplevde dette som foruroligende eller angstdrivende. I studiet til Beez og medarbeidere (7) oppga derimot 13,9 prosent ubehag ved bortfall av funksjoner på grunn av testing, og tre av pasientene ble utslitt av den intraoperative testingen. 
Den ene pasienten i denne studien husker at hun ble engstelig knyttet til at hun følte at hun rørte på seg, og at hun var redd for at dette kunne være skadelig eller forstyrrende. Wahab, Grundy og Weidmann (13) fant også at pasientene kunne være redde for å røre på seg. Milian, Tatagiba og Feigl (4) vurderte hvorvidt de peroperative opplevelsene til pasientene kunne manifesteres i posttraumatiske lidelser. Dette klarte de ikke å påvise. Pasientene i studien virker også til å ha et avslappet forhold til sine perioperative minner.

\section{Angst}

Alle pasientene i studien ga inntrykk av å tåle våken kraniotomi godt. Fem av seks sier de ville gjort det igjen, mens den sjette sier at «det var helt okay å være våken. Det gjorde meg ingenting». Manchella og medarbeidere (9) og Khu og medarbeidere (10) fant at asleep-awake-asleep-metoden tolereres godt av pasientene med positive minner. Beez og medarbeidere (7) fant at kun tre av 105 pasienter ikke ville velge våken kraniotomi igjen. Dette står i kontrast til Palese og medarbeidere (11), som fant at pasientene opplevde betydelig angst under inngrepet og måtte anstrenge seg for å «beholde kontrollen» under operasjonen.

Ingen av pasientene i denne studien oppgir betydelig angst eller redsel under operasjonen. De fortalte om hva de gjorde i forkant av operasjonen for å avlede oppmerksomheten fra det som skulle skje. Noen bruker mosjon, andre lesing og tegning som avledningsteknikker. Dette støttes av Fletcher og medarbeidere (12) og Palese og medarbeiedere (11). 
Lepola og medarbeidere (14) samt Wideheim og medarbeidere (15) beskriver også hvordan pasientene trengte tid før operasjonen til å finne sin rolle under inngrepet og å være sammen med familien. Dette reflekterer også tilbakemeldingen fra en av pasientene i studien: «Det kan jo være at man trenger noe betenkningstid før beslutningen». Hvis pasientene skal finne sin rolle og skal kunne diskutere med sin familie, og være sammen med dem før operasjonen, er man avhengig av å ha tid til det. Nettopp fordi det kan redusere pasientenes opplevelse av frykt og angst før operasjonen $(13,14)$.

\section{Fortrolighet}

Funnene i denne studien av pasientenes opplevelser med inngrepet, er sammenfallende med hva man fant hos Khu og medarbeidere (10). Manchella og medarbeidere (9) fant også at pasientene var villige til å gjennomgå dette fordi man oppfattet sikkerhetsmarginen som bedre sammenliknet med operasjon i generell anestesi. Som flere fortalte, ble de godt informert om hva som skulle skje, og dette var sammenfallende med deres opplevelser.

\section{三 «Legen har også betydning for pasientenes psykiske reaksjoner og nervøsitet underveis.»}

Fletcher og medarbeidere (12) konkluderte med at forholdet til nevrokirurgen er av stor betydning for pasientens beslutning om å gjennomføre inngrepet. Legen har også betydning for pasientenes psykiske reaksjoner og nervøsitet underveis, og hvorvidt pasienten godtok informasjonen som ble gitt. En av våre pasienter sa: «Jeg gruet meg fælt... jeg snakket med kirurgen før operasjonen, og han er helt fantastisk. Jeg ble fortalt hva som kunne skje... alt stemte!»

\section{Informasjon og forberedelse}


Pasientene i studien fortalte om opplevelser med både feilinformasjon, og mangelfull informasjon fra lokalsykehuset. De rapporterte også å ha innhentet informasjon på egen hånd, for eksempel fra internett.

Det er usikkert hvor kvalitetssikret denne informasjonen er, og det er derfor viktig å gå ut ifra at alle pasientene trenger grundig og dyptgående informasjon før et våkent inngrep. Det er viktig å rydde av veien eventuelle misforståelser, og feiloppfatninger pasientene måtte ha.

Pasientene i denne studien sier at de følte seg godt forberedt og informert etter preoperativ samtale. Manchella og medarbeidere (9) beskriver at alle pasientene følte seg godt forberedt etter den preoperative samtalen med behandlingsteamet. I studien oppga flere pasienter at de hadde ønsket seg mer informasjon, også på et detaljert nivå. Det kunne dreie seg om informasjon om hvordan hårklippen skulle være, hvor stort operasjonssnitt og hvor mange sting/hudstifter de ville våkne med, til potensielle funksjonsendringer og forventet rekonvalesensperiode. Milian og medarbeidere (16) antydet at der en uventet awareness hos kirurgiske pasienter kan lede til posttraumatiske stresslidelser, vil adekvat forberedelse av pasienter før planlagte operasjoner i våken tilstand kunne ha en beskyttende effekt mot nettopp dette.

I alle de nevnte studiene, fikk pasientene en hel dag med forberedelser dagen før inngrepet, og noen fikk også detaljert skriftlig informasjon hjem i forkant (13). Dette står litt i kontrast til den ene informanten som fortalte at i brev med innkalling til sykehuset, fikk pasienten vite at inngrepet skulle være «våken kraniotomi», uten noen videre forklaring. Dette viser at det er rom for forbedring, både i skrivene som sendes ut ved innkalling til operasjon, og ved mottak av pasientene ved innleggelse. 
Funn kan tyde på at det kan være hensiktsmessig å utarbeide et informasjonsskriv som sendes med innkallingen, hvor en informerer detaljert om våken kraniotomi og med en oppgitt kontaktperson som kan svare på spørsmål pasienten eller pårørende måtte ha. I tillegg, bør det utarbeides en mal, eller plan, for mottak av pasientene. En slik plan bør inneholde en oversikt over hvem som skal gi informasjon, hva informasjonen bør inneholde, og til hvilket tidspunkt dette skal gjøres. På denne måten kan man sørge for at pasientene har de beste forutsetningene til å forberede seg (17).

\section{Venting}

Pasientene opplever ventingen som en stor belastning. De venter på diagnose, på operasjonsdato, sykehusinnleggelse og de venter på å få vite hva som skal skje når de har ankommet sykehuset. Å håndtere ventingen oppleves som en stor belastning av flere. Jagadeesh og Bernstein (18) beskriver hvordan pasientene opplever å vente på nevrokirurgisk konsultasjon. En av pasientene deres beskriver dette som en berg-og-dal-bane. Det er et element av frykt, noe stort ukjent, som å være i midten av en mental ørken i sandstorm, og uten å vite hva man skal gjøre. Noen av pasientene opplevde også at symptomene ble verre i venteperioden.

Jagadeesh og Bernstein (18) peker på at å støtte pasientene emosjonelt i ventetiden hadde en angstdempende effekt. Samtidig peker de på at man kan korte ned på ventetiden ved å være mer effektiv i å henvise pasienter videre, og prioritere pasienter til konsultasjon slik at ventetiden blir så kort som mulig.

\section{Konklusjon}

Pasientene opplevde lite smerter og angst per- og postoperativt. Ingen rapporterte om minner som i ettertid har vært vanskelig å fordøye. Pasientene var også fortrolig med metoden «våken kraniotomi», og forsto hvorfor man gjør det i våken tilstand. Pasientene oppga å ha en sterk tillit til fagpersonell ved sykehuset. 
Pasientene påpekte behovet for mer detaljert preoperativ informasjon om hva de kunne forvente seg etter operasjonen. For flere av pasientene var ventingen før innleggelsen den største påkjenningen. Kunnskap om belastningen knyttet til ventetiden for pasienter, bør føre til økt oppmerksomhet omkring hva som kan lette eller bedre ventetiden.

\section{Referanser}

1. Sacko O, Lauwers-Cances V, Brauge D, Sesay M, Brenner A, Roux FE. Awake craniotomy vs surgery under general anesthesia for resection of supratentorial lesions. Neurosurgery. 2011;68(5):1192-8. DOI: 10.1227/NEU.0b013e31820c02a3. Tilgjengelig fra: https://www.ncbi.nlm.nih.gov/pubmed/21273923 (nedlastet 06.11.2017).

2. Brown T, Shah AH, Bregy A, Shah NH, Thambuswamy M, Barbarite E, Fuhrman T, Komotar RJ. Neurosurg Anesthesiol. 2013;25(3):240-7. DOI: 10.1097/ANA.0b013e318290c230. Tilgjengelig fra: Awake craniotomy for brain tumor resection: the rule rather than the exception? (nedlastet 06.11.2017)

3. Chacko AG, Thomas SG, Babu KS, Daniel RT, Chacko G, Prabhu K, Cherian V, Korula G. Awake craniotomy and electrophysiological mapping for eloquent area tumours. Clin Neurol Neurosurg. 2013;115(3):329-34.DOI:

10.1016/j.clineuro.2012.10.022, Tilgjengelig fra: https://www.ncbi.nlm.nih.gov/pubmed/23177182 (nedlastet 06.11.17)

4. Milian M, Tatagiba M, Feigl GC. Patient response to awake craniotomy - a summary overview. Acta Neurochir (Wien). 2014 156(6):1063-70. DOI: 10.1007/s00701-014-2038-4. Tilgjengelig fra: https://www.ncbi.nlm.nih.gov/pubmed/24595540 (nedlastet 06.11.2017). 
5. Kvale S, Brinkmann S. Det kvalitative

forskningsintervju (2. utg.). Oslo: Gyldendal

akademisk; 2012.

6. Graneheim UH, Lundman B. Qualitative content analysis in nursing research: concepts, procedures and measures to achieve trustworthiness. Nurse Educ Today. 2004;24(2):105-12. Tilgjengelig fra:

https://www.ncbi.nlm.nih.gov/pubmed/14769454 (nedlastet: 06.11.2017).

7. Beez T Boge K, Wager M, Whittle I, Fontaine D, Spena G, Braun S, Szelényi A, Bello L, Duffau H, Sabel M. Tolerance of awake surgery for glioma: a prospective European Low Grade Glioma Network multicenter study. Acta Neurochirurgica, 2013;155(7):1301-8 DOI: 10.1007/s00701-013-17590 Tilgjengelig fra: https://www.ncbi.nlm.nih.gov/pubmed/23689968 (nedlastet 06.11.2017).

8. Whittle IR, Midgley S, Georges H, Pringle AM, Taylor R. Patient perceptions of "awake" brain tumour surgery. Acta Neurochir 2005;147(3):275-7

Tilgjengelig fra:

https://www.ncbi.nlm.nih.gov/pubmed/15627921 (nedlastet 06.11.17).

9. Manchella S, Khurana VG, Duke D, Brussel T, French J, Zuccherelli L. The experience of patients undergoing awake craniotomy for intracranial masses: expectations, recall, satisfaction and functional outcome BR J Neurosurg. 2011;25(3) 391-400.

Tilgjengelig fra:

https://www.ncbi.nlm.nih.gov/pubmed/21615221 (nedlastet 06.11.17). 
10. Khu KJ, Doglietto F, Radovanovic I, Taleb F, Mendelssohn D, Zadeh G, Bernstein M. Patients' perceptions of awake and outpatient craniotomy for brain tumor: a qualitative study. J Neurosurg. 2010;112(5):1056-60.

DOI:10.3171/2009.6.JNS09716. Tilgjengelig fra: https://www.ncbi.nlm.nih.gov/pubmed/19612973 (nedlastet 06.11.17).

11. Palese A, Skrap M, Fachin M, Visioli S, Zannini L. The experience of patients undergoing awake craniotomy: in the patients' own words. A qualitative study. Cancer Nurs.2008 31(2):166-72.

DOI:10.1097/01.NCC.0000305699.97625.dc.

Tilgjengelig fra:

https://www.ncbi.nlm.nih.gov/pubmed/18490893 (nedlastet 06.11.2017).

12. Fletcher KJ, das Nair R, Macniven JA, Basu S, Byrne P. An interpretative phenomenological analysis of the patient experience of awake craniotomy: Brain tumour diagnosis to discharge. BR J Health Psychol. 2012;17(4):828-42. DOI: 10.1111/j.20448287.2012.02079.x. Tilgjengelig fra: http://onlinelibrary.wiley.com/doi/10.1111/j.20448287.2012.02079.x/abst... (nedlastet 06.11.17).

13. Wahab S, Grundy P, Weidmann C. Patient experience and satisfaction with awake craniotomy for brain tumours. British Journal of Neurosurgey, 2011; 25(5):606-13. DOI: 10.3109/02688697.2011.568642. Tilgjengelig fra:

https://www.ncbi.nlm.nih.gov/pubmed/21591851 (nedlastet: 06.11.17).

14. Lepola I, Toljamo M, Aho R, Louet T, J Neurosci Nurs. 2001;33(3):143-7. Being a brain tumour patient: a descriptive study of patients' experiences. Tilgjengelig fra: https://www.ncbi.nlm.nih.gov/pubmed/11413659 (nedlastet: 06.11.17). 
15. Wideheim AK, Edvarsson T, Påhlson A, Ahlstrøm

G. A family's perspective on living with a highly

malignant brain tumor. Cancer Nurs. 2002;25 (3):236-

44. Tilgjengelig fra:

https://www.ncbi.nlm.nih.gov/pubmed/12040233

(nedlastet 06.11.17).

16. Milian M, Luerding R, Ploppa A, Decker K, Psaras

T, Tatagiba M, Gharabaghi A, Feigl GC. "Imagine

your neighbor mows the lawn": a pilot study of

psychological sequelae due to awake craniotomy:

clinical article. J Neurosurg. 2013; 118(6):1288-95.

DOI: 10.3171/2013.2.JNS121254. Tilgjengelig fra:

https://www.ncbi.nlm.nih.gov/pubmed/23540268

(nedlastet 06.11.2017).

17. Bolton V, Brittain. Patient information provision:

its effect on patient anxiety and the role of health

information services and libraries. M Health Libr Rev.

1994;11(2):117-32. Tilgjengelig fra:

https://www.ncbi.nlm.nih.gov/pubmed/10172100

(nedlastet 06.11.2017).

18. Jagadeesh H, Bernstein M. Patients' anxiety

around incidental brain tumors: a qualitative study.

Acta Neurochirurgica. 2014;156(2):375-81. DOI.

10.1007/s00701-013-1935-2 Tilgjengelig fra:

https://www.ncbi.nlm.nih.gov/pmc/articles/PMC3898365/

(nedlastet 06.11.2017). 